\title{
Cross-Country Differences in Systemic Risk: The Role of National Culture
}

\author{
Francesca Battaglia \\ Department of Management Studies and Quantitative Methods \\ University of Naples "Parthenope", Italy \\ Francesco Busato \\ Department of Economic and Legal Studies \\ University of Naples "Parthenope", Italy \\ Maria Manganiello \\ Department of Economic and Legal Studies \\ University of Naples "Parthenope", Italy
}

\begin{abstract}
This paper aims to provide a summary of the state of the art of systemic risk research while focusing on its relationship with national culture. Specifically, it offers new insight into the role of national culture in the banking industry. To this end, after a discussion of main systemic risk measures, the paper suggests that there is a lack of systemic risk indicators relying on the national culture dimension, although there exists empirical evidence on the causal relationship between national culture and bank risk-taking.
\end{abstract}

Keywords: systemic risk, financial markets, financial stability, financial crisis, forecasting, national culture.

JEL classification: C53, G12, G21, G29.

\section{Introduction}

The international financial crisis made us thinking much harder - not only about what systemic risk means, but it also showed its relevance for policymakers and regulators. Following the joint work of the FSB, BIS IMF "Guidance to Assess the Systemic Importance of Financial Institutions, Markets and Instruments: Initial Considerations" (2009), systemic risk is defined as "a risk of disruption to financial services that is caused by an impairment of all or parts of the financial system and has the potential to have serious negative consequences for the real economy." According to the aforementioned definition, when a bank loses money from a risky investment, the dimension is not systemic; on the contrary, systemic risk materializes when financial institutions fail, infrastructures collapse or there is an increase of the cost of financial services, which can lead to severe adverse implications also for many other market participants.

Many recent studies (e.g., Silva et al. 2017, Acemoglu et al. 2015) focus on the 2007-2009 global financial crisis and on the 2010-2011 sovereign debt crisis (e.g., Black et al., 2016, Bolton et al. 2011). In the aftermath of these crises, several studies on the financial system and financial risks have been conducted to date.

Previous research has long developed a theoretical framework to identify the main mechanisms underlying systemic risk (e.g., Bernanke and Gertler (1989), Rochet and Tirole (1996a), up to Allen and Gale (2000b) and Acharya (2001)). In recent years, the need to answer to imminent regulatory issues has given rise to an extensive literature focused on systemic risk.

Several authors (Allen et al., 2000; Anginer et al., 2014) rely on specific sources of systemic risk, such as contagion, bank runs, or liquidity crises. This approach is based on several families of qualitative models, providing forecasts that can be confirmed by empirical analyzes, often based on supervisory data. In line with this strand of literature, a variety of tools have been introduced to monitor selected different channels of systemic risk and realign banks' behavior with financial stability. Other authors (Acharya. et al., 2010; Adrian et al., 2016) focus on global measures of systemic risk, potentially encompassing all mechanisms explored by the previous stream of literature. However, as cross-country cultural differences affect bank risk-taking behavior (Mourouzidou-Damtsa et al., 2019; Boubakri et al., 2017; Ashraf et al., 2016; Kanagarethnam et al., 2011; Kwok et al., 2006), this paper argues that national cultural could potentially play a crucial role on systemic risk. 
Consequently, this paper focuses on the relationship between national cultural and systemic risk. To date, we are not aware of other contributions to discussing this issue. The remainder of the paper is organized as follows. Section 2 provides the theoretical framework underlying systemic risk. Section 3 analyses the main measures used to predict and forecast this risk from a researcher-oriented perspective. Section 4 explores the dimensions of national culture. Conclusions are drawn in Sections 5. Section 6 suggests avenues for future research.

\section{Classical Perspective on Systemic Risk}

The subprime crisis was the most severe financial crisis since the Great Depression. It caused significant economic stresses worldwide, and in response, new financial market regulations were adopted in many countries.

An important task of research is to identify what characteristics of financial institutions and market, in general, have a relatively more significant impact on systemic risk and on amplifying or dampening exogenous shocks. Caccioli et al. (2009) and Dimsdale (2009) discuss financial instruments with the potential to create large fluctuations and instabilities in the financial system, which can bring the market to a state where trading volumes expand rapidly and saturate the investor demand.

According to Battaglia and Gallo (2013), securitization increases the likelihood of banks becoming systematically riskier. Thus, in severe scenarios, banks that securitize would have higher expected losses on average. This aspect would suggest that the risk transfer by securitization is not significant about the risk maintained by the originating bank. In this context, also the size of the bank and asset growth is critical determinants of the risk exposure of a bank.

Moreover, leverage increases the individual risk of banking firms, implying a higher vulnerability to financial shocks. On the other hand, the level of leverage is beneficial to the health of banks individually but detrimental to financial stability (Papanikolau and Wolff, 2014). According to Anginer et al. (2014a), banking competition also influences systemic risk in a stable negative relationship. Increased competition makes the system less vulnerable to shocks as it encourages banks to diversify risks. In countries where supervision and monitoring are scarce, banking systems are more fragile as they trigger policies that limit and undermine competition. These researchers conclude that the negative effect of lack of competition can be mitigated by an institutional environment that allows efficient public and private monitoring (Anginer et al., 2014a).

The implications of the global financial crisis have seen rapid growth in research on the relationship between the capitalization levels of banks, their contribution to systemic risk through the assumption of individual risks, and the extent to which the latter is influenced by governance structures below. Intuitively, it could be concluded that more capital always makes banks safer. However, this claim would be based on the assumption that banks' behavior would remain unchanged. If not, results may be different; indeed, relationships between capital levels, risk, and governance are complicated. Some contributions took a detailed look at the relationship between management and risk-taking. Ownership structures are relevant, with corporate governance structures, more shareholder focused being related to higher levels of systemic risk. Schwarcz (2017) argues that excessive corporate risk-taking results from managerial decisions.

Therefore, there is a corporate governance problem at the root. An extensive empirical literature has documented that banks with a reliable corporate governance mechanism have higher corporate valuations, higher financial performance, higher equity returns and lower systemic risk (Caprio et al., 2007; de Andres and Vallelado, 2008; Laeven and Levine, 2009; Webb Cooper, 2009). For example, if a bank has a strong risk appetite, it can naturally take on more risk by creating a risk committee on the board of directors, increasing its involvement.

\section{Forecasting systemic risk: the researcher-oriented perspective}

In a period of systemic crisis, institutions with relatively higher exposure to systemic risk should exhibit poorer performance than those with low exposure. Therefore, in times of crisis, a non-timely measure of systemic exposure to risk should be negatively correlated with returns on future assets or securities.

Regulators need to quantify systemic risk. They are interested in identifying the institutions that contribute the most to the risk of the system at a given point in time (cross-section dimension), as well as monitoring how the risk of a given institution evolves (time-series dimension). There are several measures of systemic risk exposure. Still, we will compare three methods of estimating the systemic risk that represent the most central metrics in the systemic risk literature: Marginal Expected Shortfall (MES) and Systemic Expected Shortfall (SES)of Acharya et al. (2010), the Delta Conditional Value-at-Risk ( $\triangle \mathrm{CoVaR})$ of Adrian and Brunnermeier (2016) and Granger Causality test of Billio et al. (2010).

\subsection{Marginal Expected Shortfall (MES) and Systemic Expected Shortfall (SES)}


The MES, initially proposed by Acharya et al. (2010), measures the average return of financial institutions on days when the market as a whole is in the tail of its return distribution. MES is calculated at the $5 \%$ level over the previous year of return data:

$$
\operatorname{MES}_{5 \%}^{b}=\frac{1}{\# \text { days }} \sum_{\text {t:systemic in } 5 \% \text { tail }} R_{t}^{b}
$$

where $\mathrm{R}_{\mathrm{t}}^{\mathrm{b}}$ represents the daily returns of the institution. The Systemic Expected Shortfall (SES) of an institution describes its "propensity to be undercapitalized when the system as a whole is undercapitalized." The authors derive the two key components of SES: Marginal Expected Shortfall (MES) and Leverage (LVG). These components are used to proxy for SES. Acharya et al. (2010) estimate leverage using the following approximation:

$$
\mathrm{LVG}=\frac{\text { book assets-book equity + market equity }}{\text { market value of equity }}
$$

SES examines how an institution is affected by the entire market rather than how individual institutions affect each other as Granger Causality does. Furthermore, SES utilizes stock return, while $\triangle \mathrm{CoVaR}$ measures changes in the market value of an institution's assets.

\subsection{Delta Conditional Value-at-Risk ( $\triangle$ CoVaR)}

The $\triangle \mathrm{CoVaR}$ by Adrian and Brunnermeier (2016) is a popular systemic risk measure. CoVaR estimates the contribution of a single institution to the overall losses suffered by the financial system, given a crisis event. Exposure $\triangle \mathrm{CoVaR}$ provides an estimate of the change in an institution's VaR, given an industry-wide systemic crisis. The authors define Exposure CoVaR as "institution j's increase in $\mathrm{VaR}$ in the case of a financial crisis." I denote the financial system as $s$. Exposure CoVaR is given by the $\mathrm{q}^{\text {th }}$-quantile of the conditional probability distribution:

$$
\operatorname{Pr}\left(\mathrm{X}^{\mathrm{j}} \leq \mathrm{CoVaR} R_{q}^{j \mid C\left(X^{s}\right)} \mid \mathrm{C}\left(\mathrm{X}^{\mathrm{s}}\right)\right)=\mathrm{q}
$$

where $\mathrm{X}^{\mathrm{j}}$ is the variable for which the value-at-risk of institution $\mathrm{j}$ is defined, $\mathrm{C}\left(\mathrm{X}^{\mathrm{s}}\right)$ is a tail event within the system and $\mathrm{CoVa} R_{q}^{j \mid C\left(X^{s}\right)}$ is the $\mathrm{VaR}$ of an institution conditional on the state of the financial system. The variable $\mathrm{q}$ denotes a probability level corresponding to the left tail of the distribution of institution-level asset returns. This value is typically set to $1 \%$. Further, the system's contribution to $\mathrm{j}$, which is in turn $\mathrm{j}$ 's exposure to the system, is given by:

$$
\Delta \mathrm{CoVaR} R_{q}^{j \mid s}=\mathrm{CoVa}_{q}^{j \mid X^{s}=\operatorname{VaR}_{q}^{i}}-\mathrm{CoVaR}_{q}^{j \mid X^{s}=\text { Median }^{s}}
$$

Then, denoting a set of macroeconomic conditioning variables as $\mathbf{M}_{\mathrm{t}-1}$, Adrian, and Brunnermeier (2016) estimate:

$$
X_{j}=\beta^{j \mid s} X_{s}+\gamma^{j \mid s} M_{t-1}+\alpha^{j \mid s}
$$

The generated coefficients are then used to estimate the $\mathrm{VaR}$ and $\mathrm{CoVaR}$ of the institution and the system at the median and $\mathrm{q}=1 \%$ levels. Finally, $\beta^{\mathrm{j} \mid \mathrm{s}}$ is used to calculate Exposure CoVaR:

$$
\Delta \operatorname{CoVa} R_{q}^{j \mid C\left(X^{s}\right)}=\beta^{\mathrm{j} \mid \mathrm{s}}\left(\mathrm{Va} R_{t}^{s}(\mathrm{q})-\mathrm{Va} R_{t}^{s}(50 \%)\right)
$$

In detail, Adrian and Brunnermeier (2016) measure the financial sector's VaR, given that a bank has had a VaR loss $(\mathrm{CoVaR})$, using quantile regressions. To construct the underlying asset, $\Delta \mathrm{CoVaR}$ uses market equity data and book value of the debt.

Although regulators also have to worry about expected losses beyond the VaR threshold, Adrian and Brunnermeier's (2016) approach has the advantage of framing the analysis using this regulatory tool.

Adrian and Brunnermeier's (2016) CoVaR measure is conceptually different from SES measure in that it examines the system's stress conditional on an individual firm's stress. In contrast, SES examines a financial firm's stress conditional on systemic pressure. In comparison to CoVaR, SES measure has the advantage that the conditioning set is held constant for all firms (i.e., the existence of a financial crisis).

\subsection{Granger Causality test}


Billio et al. (2010) use monthly returns on hedge funds, banks, broker-dealers, and insurance companies to develop several measures of interconnectedness based on Granger causality test. In general, this measure doesn't address how an individual institution contributes to the overall risk or how systemic risk affects an institution individually.

For this reason, taking into account this issue, the authors modify the Granger Causality measure so to provide direct estimates of statistical connectivity within a system of financial institutions. They show that banks have played a predominant role in transmitting shocks compared to other types of financial institutions. Following Billio et al. (2010), linear inter-relationships are represented as:

$$
\begin{aligned}
& X_{t}=\sum_{j=1}^{m} a_{j} X_{t-j}+\sum_{j=1}^{m} b_{j} Y_{t-j}+\epsilon_{t} \\
& Y_{t}=\sum_{j=1}^{m} c_{j} X_{t-j}+\sum_{j=1}^{m} d_{j} Y_{t-j}+\eta_{t}
\end{aligned}
$$

Within the context of this test, Y Granger causes $\mathrm{X}$ when $b_{j}$ is not equal to zero.

Similarly, when $c_{j}$ is not equal to zero, the test implies that X Granger causes Y. However, when both $b_{j}$ and $c_{j}$ are not equal to zero, no information can be discerned from the test as to which variable causes the other. These tests address linear relations between institutions. Even if the test is inconclusive, a non-linear relationship may still exist. The statistical concept of causality within this measure is based on prediction. If a signal Y "Granger-causes" (or "Gcauses") a signal $\mathrm{X}$, then past values of $\mathrm{Y}$ should contain information that helps predict $\mathrm{X}$ above and beyond the information contained in past values of $\mathrm{X}$ alone.

\subsection{Assessing strengths and limitations of systemic risk measures}

Several measures of systemic risk have been proposed in recent years, and they are aimed at pointing out, defining, and measuring different dimensions of systemic risk. At the bank's portfolio level, risk measures typically used are valueat-risk (VaR) and expected shortfall (ES), that can be adapted to assess systemic exposure of the banking sector.

Systemic risk crucially depends on the measurement of the probability distribution of a systemic event, and its different measures have the task to gauge the increase in tail due to the spreading of financial distress across institutions.

The two main measures that fall within this group are $\triangle \mathrm{CoVaR}$ mentioned above by Adrian and Brunnermeier (2016) and MES by Acharya et al. (2017). In detail, the CoVaR of an institution is the Var of its asset value (for a given confidence interval) conditioned by another event. The $\Delta \mathrm{CoVaR}$, on the other hand, is provided by the difference between the CoVaR of the financial system (conditioned by the fact that the institution is in difficulty) and the CoVaR of the same financial system in the median state of the institution. It measures the contribution of each institution to systemic risk.

Despite the accuracy of this measure, Adrian and Brunnermeier (2016) demonstrate that it may not be sufficient to rely only on the $\triangle \mathrm{CoVaR}$ to assess in depth the systemic risk of the financial sector as this measure is not sensitive neither to leverage nor to size. As regards the second systemic risk measure, MES derives from Expected Shortfall, which is the expected loss conditional on the loss being greater than the VaR. The MES represents the institution's marginal contribution to the expected deficit of the financial system, conditional on the market, taking a loss greater than its Value-at-Risk for a given confidence level. Thus, an institution with high levels of ESM is more likely to be undercapitalized in corrupt economic states and contributes more to the aggregate risk of the financial system.

The two measures just analyzed, $\triangle \mathrm{CoVaR}$ and MES, although having similar nature, can be seen as complementary to each other as they measure two sides of the same coin. While MES explains the risk of an institution conditioned by systemic stress, $\triangle \mathrm{CoVaR}$ is intended to measure the risk of the financial system posed by an institution. However, there is an essential difference between the two. While the former considers conditional distributions of equity returns, the latter is calculated based on actual distributions of profits and losses.

$\triangle \mathrm{CoVaR}$ and MES, although they are valid measuring instruments, cannot adequately take into account the size of the impact on the entire system.

Other systemic risk measures were found to be complete and adequate. In particular, the SES by Acharya et al. (2017) shows that systemic risk of an institution is equal to the product of two relevant variables: MES and leverage.

In detail, the SES considers the "size" of a firm's exposure to systemic risk, (as proxied by its leverage), the MES (proxying the expectation of a firm's contribution to realized systemic risk) and two interaction components (accounting for excess returns due to increased credit risk and excess cost of financial distress). 
However, countries differ alongside the structure of their financial system, and the systemic risk measures previously analyzed might not take into account another important dimension: national culture.

\section{A new avenue for further investigations: national culture dimension}

Hartog et al. (1999) define the national culture as "shared motives, values, beliefs, identities, and interpretations or meanings of significant events that result from common experiences of members of collectives and are transmitted across age generations."

Culture impacts transfer, people's behaviors, attitudes, ideology, business, and government relations. Perhaps most important, culture affects how people think and behave, thus playing a significant role. Knowledge of a country's national culture is essential for increasing international affairs as it can affect the entire financial system, just as a severe financial crisis can have dramatic effects on a country's culture and economic relations.

The same national culture is capable of influencing decisions of managers or influencing economic and financial development. Many researchers, in the recent past, focused on the relationship between corporate culture and company effectiveness (Deal and Kennedy, 1982; Schein, 1992; Hartnell, Ou and Kinicki, 2011), or on the interaction between corporate orientation and company performance (Kotter, 2008; Sackmann, 2010; Hartnell, Ou and Kinicki, 2011) or on how a company's performance can be influenced by national/regional culture and corporate culture (e.g., Boubakri, Mirzaei and Samet, 2017; Chen, Podolski, and Veeraraghavan, 2017) or, eventually, on how cultural values impact the financial results of companies (Guiso, Sapienza and Zingales, 2009; Bottazzi, Da Rin and Hellmann, 2010; Chui, Titman and Wei, 2010.)

Many interactions between markets can be explained through national culture, so it is crucial to analyze the relationship between culture and financial intermediaries. This paper provides a review of selected studies on national culture to understand its impact on the behaviors of financial intermediaries. This impact is critical to analyze the markets and the financial system.

For example, Mourouzi-Damtsa, Milidonis, and Stathopoulos (2019) investigate the relationship between national cultural values and bank risk. They find evidence of an economically significant association between cultural values and domestic bank risk. In particular, they argue that national culture influences the risk appetite of bank managers directly. Still, it also has an indirect effect since bankers should satisfy the needs and risk preferences of their customers.

They consider a sample of 99 banks in 19 European countries, which they analyze for 20 years (1995-2014). They use the national culture framework of the World Values Survey (WVS), and the three cultural values under investigation are individualism, hierarchy, and trust.

They find that there is a positive association between the cultural values of individualism and hierarchy and domestic bank risk-taking, but a negative relationship between trust and risk.

Individualism can be defined as a preference for a social framework in which individuals are expected to take care of themselves and their immediate families. Countries characterized by individualistic cultural norms prefer individual advancement. In contrast, countries with collectivist cultures give priority to workgroup goals over individual gain, and they represent a preference for a framework in society in which, in exchange for unquestioning loyalty, individuals can expect their families to look after them. Therefore, banks operating in individualistic societies have little consideration about the impact of bank risk on the stability of the national financial system because shareholder's primary objective is wealth maximization (Yahanpath, 2011).

Banks operate in a competitive environment; for this reason, customer trust is necessary for banks (Ratnovski, 2013) to maintain and increase deposits. When trust in a country's financial institutions is low, it is observed significant deposit withdrawals from the domestic banking system, which limits the ability of banks to execute their primary role as financial intermediaries (Coupé, 2011). Finally, in hierarchical societies, lower ranked employees follow management instructions without questioning them. In contrast, in egalitarian societies, management and employees view themselves as equals; thus, employees are more likely to be concerned about the financial stability of the banking sector.

Many types of research, on the other hand, emphasize that the realization of comparative advantage should depend on the sensitivity of a country's investors towards risk and uncertainty. Individuals vary in their perception as well as in the tolerance of uncertainty.

As reported by Hofstede (2001), "the Uncertainty Avoidance dimension expresses the degree to which the members of a society feel uncomfortable with uncertainty and ambiguity. The fundamental issue here is how a society deals with the fact that the future can never be known. Countries exhibiting strong Uncertainty Avoidance maintain rigid codes of 
belief and behavior and are intolerant of unorthodox behavior and ideas. Weak Uncertainty Avoidance societies maintain a more relaxed attitude in which practice counts more than principles".

For example, Kwok and Tadesse (2006) show that the degree of risk tolerance inherent in national culture can influence the configuration of a country's financial system. Banking financial systems with a more exceptional ability to reduce risk are more likely to be compatible with national cultures characterized by strong prevention of uncertainty. In contrast, countries with a high risk tolerance are characterized by a market-based system as higher risks lead to higher returns.

Kanagaretnam, Lim, and Lobo (2011) examine the extent to which cultural differences influence bank risk-taking using a sample of banks from 45 countries selected from the 50 countries listed in Hofstede (2001). They also explore the effects of national culture on bank financial trouble during the recent financial crisis. They focus on two dimensions of national culture identified by Hofstede (2001), uncertainty avoidance and individualism. Low uncertainty-avoidance societies socialize their people into accepting or tolerating uncertainty. Individuals living in such societies are less averse to taking risks. By contrast, people living in high uncertainty avoidance societies tend to have a higher level of anxiety, which may manifest in greater nervousness and aggressiveness. These people prefer a more predictable environment. Long-standing literature in economics has focused on the distinction between collective decision making and individual-based decision making. It finds that groups are more risk averse than individuals in high-risk situations. Following recent literature, Kwok and Tadesse (2006) document that besides the influence of legal systems, the configuration of financial systems is also related to uncertainty avoidance, a dimension of national cultures, and also they establish a link between the culture literature and the finance literature, suggesting a cross-disciplinary explanation of financial systems. In particular, Kwok and Solomon argue that countries differ in the way their financial activities are organized.

In Anglo-Saxon countries such as the U.S. and U.K., financial systems are dominated by stock markets, whereas, in Continental Europe and Japan, banks play a predominant role. They introduce national culture as a potential explanation of the diversity in financial system configurations. Specifically, they conjuncture that countries with stronger uncertainty avoidance as a cultural trait are more likely to be associated with a bank-based financial system. To relate national culture to the configuration of financial systems, they are particularly interested in Hofstede's cultural dimension of uncertainty avoidance. The Uncertainty Avoidance Index (UAI) assesses how people handle uncertainty as future events cannot be correctly predicted. In this study, after controlling for the legal explanation, they examine the role of culture in explaining cross-country variations in financial system design empirically. They find that countries characterized by higher uncertainty avoidance are more likely to have a bank-based system.

Ashraf, Zheng, Arshad (2016), employ an international sample of 1,981 banks from 75 countries over the period 20012007 to analyze the direct effects of national cultural differences on bank risk-taking, after controlling for indirect cultural effects. They measure national culture with four dimensions-uncertainty avoidance, individualism vs. collectivism, masculinity vs. femininity, and power distance- from Hofstede's framework of national culture (Hofstede 1980, 2001; Hofstede et al. 2010). They show that bank risk-taking is higher in countries that have high individualism, low uncertainty avoidance, and low power distance cultural values.

Despite above international studies, it should be noted that while several studies argue a correlation/causality between corporate orientation and firm performance, or a relation between national cultural and bank risk-taking, there is no empirical research investigating the relationship between national culture and systemic risk. Many researches focused their attention on national culture about different types of financial risks, but not to systemic risk.

\section{Conclusions}

From the analysis of prior studies analyzing the determinants of systemic risk, it is clear that there are not empirical researches investigating the impact of national/regional culture on systemic risk.

According to this evidence, this paper suggests that it is important to fill this gap in order to mitigate this kind of risk. Our point of view is that cultural differences among countries could potentially influence the level of systemic risk and could help to explain the financial crises that occurred in the last decade. In particular, systemic risk should be relatively higher for European financial banks in countries with low uncertainty aversion, low tolerance for hierarchical relationships, and high individualism (Ashraf et al., 2016; Kanagaretnam et al., 2011; Kwok et al., 2006)

Since the risk estimation is a crucial topic for policymakers, who are looking for tools to monitor the building up of risks and quantify the negative externalities imposed by systemic institutions on the whole financial system. Ideally, regulators need timely specific measures of systemic risk to capture the underlying economic mechanisms and to be used as inputs for regulatory tools. Thus, going forward, it is important to have an adequate measure of the systemic 
risk exposure of financial institutions. Furthermore, for the same reason, it is necessary to identify the main factors affecting the level of systemic risk in order to regulate it better.

\section{Further research}

Systemic risk is an excellent example of a field in which academic research and financial institutions cross-fertilize. This paper suggests analyzing the role of national culture to identify better going forward the vulnerabilities of the financial system and to inform regulators worldwide on the complexities and challenges of having uniform regulations on risks across countries in light of the presented evidence. Furthermore, since many countries have a different financial system, existing systemic risk measures do not consider an important dimension: the national culture. This paper, therefore, argues that researchers should give greater consideration to the interactions among cultural dimensions and the simultaneous influence of bank runs, or liquidity crises on the financial system. These issues represent pressing tasks for regulators in order to predict systemic risk and to mitigate its consequences on the whole financial system eventually.

\section{References}

Acemoglu, D., Ozdaglar, A., \& Tahbaz-Salehi, A. (2015) "Systemic risk and stability in financial networks". American Economic Review, 105(2), 564-608.

Acharya, V. V., (2001) "A Theory of Systemic Risk and Design of Prudential Bank Regulation," (Unabridged) Working Paper, New York University - Stern School of Business.

Acharya, V. V., Pedersen, L. H., Philippon, T. \& Richardson, M., (2009) "Regulating Systemic Risk," Chapter 13 in Restoring Financial Stability: How to Repair a Failed System, editors Viral V. Acharya and Matthew Richardson, New York University Stern School of Business, John Wiley and Sons, March 2009.

Acharya, V.V., Pedersen, L. H., Philippon, T., \& Richardson, M. (2010) "Measuring systemic risk." SSRN Eletron. J. May, 1-46.

Acharya, V. V., Cooley, T., Richardson, M., and Walter, I., (2010) "Manufacturing Tail Risk: A Perspective on the Financial Crisis of 2007-09". Foundations and Trends in Finance, Volume 4, forthcoming.

Adrian, T., \& Brunnermeier, M. K., (2016) "CoVaR." The American Economic Review, 106(7), 1705-1741.

Allen, F., \& Gale, D., (2000) "Financial contagion." Journal of political economy, 108(1), 1-33.

Anginer, D., Demirguc-Kunt, A., Zhu, M., (2014a) "How does deposit insurance affect bank risk? Evidence from the recent crisis". J. Bank. Finance, 48(1), 312-321.

Ashraf, B. N., Zheng, C., \& Arshad, S., (2016) "Effects of national culture on bank risk-taking behavior." Research in International Business and Finance, 37, 309-326.

Battaglia, F., \& Gallo, A., (2013) "Securitization and systemic risk: An empirical investigation on Italian banks over the financial crisis." International Review of Financial Analysis, 30, 274-286.

Bernanke, B., \& Gertler, M., (1989) "Agency costs, net worth and business fluctuations." In Business Cycle Theory. Edward Elgar Publishing Ltd.

Billio, M., Getmansky, M., Lo, A. W., \& Pelizzon, L., (2010) "Econometric measures of systemic risk in the finance and insurance sectors." National Bureau of Economic Research, No. w16223.

Black, L., Correa, R., Huang, X., \& Zhou, H. (2016) "The systemic risk of European banks during the financial and sovereign debt crises." Journal of Banking \& Finance, 63, 107-125.

Bolton, Patrick and Olivier Jeanne (2011) "Sovereign default risk and bank fragility in financially integrated economies," IMF Economic Review, 59, 162-194.

Bottazzi, L., Da Rin, M., \& Hellmann, T., (2010) "The Importance of Trust for Investment: Evidence from Venture Capital". Working Paper, No 325, Milano: IGIER-Università Bocconi.

Boubakri, N., Mirzaei, A., \& Samet, A., (2017) "National culture and bank performance: Evidence from the recent financial crisis." Journal of Financial Stability, 29, 36-56.

Caccioli, F., Marsili, M., \& Vivo, P., (2009) "Eroding market stability by proliferation of financial instruments." The European Physical Journal B, 71(4), 467.

Caprio, G., Laeven, L., \& Levine, R., (2007) "Governance and bank valuation." Journal of Financial Intermediation, 16, 584-617.

Chen, Y., Podolski, E. J., \& Veeraraghavan, M., (2017) "National culture and corporate innovation." Pacific-Basin Finance Journal, 43, 173-187.

Chui, A. C., Titman, S., \& Wei, K. J., (2010) "Individualism and momentum around the world." The Journal of Finance, 65(1), 361-392. 
Coupé, T., (2011) "Mattresses versus Banks - The Effect of Trust on Portfolio Composition." Kyiv School of Economics. Discussion Paper No. 40, Kyiv, Ukraine.

de Andres, P., Vallelado, E., (2008) "Corporate governance in banking: the role of board of directors." J. Bank. Finance,32, 2570-2580.

Deal, T. E., \& Kennedy, A. A., (1982) "Corporate cultures: The rites and rituals of organizational life." Reading/T. Deal, A. Kennedy. -Mass: Addison-Wesley, 2, 98-103.

Di Cesare, A., \& Rogantini, P. A., (2018). "A survey of systemic risk indicators". Working Paper, No. 458, Banca D'Italia.

Dimsdale, N., (2009) "The financial crisis of 2007-2009 and the British experience". Oxonomics, 4 (1), 1-9.

European Central Bank, Systemic Risk (2009) "Clare Distinguished Lecture in Economics and Public Policy" by JeanClaude Trichet, President of the ECB organized by the Clare College, University of Cambridge.

Guiso, L., Sapienza, P., \& Zingales, L., (2009) "Cultural biases in economic exchange?". The Quarterly Journal of Economics, 124(3), 1095-1131.

Hartnell, C. A., Ou, A. Y., \& Kinicki, A., (2011). "Organizational culture and organizational effectiveness: a metaanalytic investigation of the competing values framework's theoretical suppositions." Journal of Applied Psychology, 96, 677-694.

Hartog, D. N., House, R. J., Hanges, P. J., Ruiz-Quintanilla, S. A., Dorfman, P. W., Abdalla, I. A., \& Akande, B. E., (1999) "Culture specific and cross-culturally generalizable implicit leadership theories: are attributes of charismatic/transformational leadership universally endorsed?". The Leadership Quarterly, 10(2), 219-256.

Hofstede, G., (1980) "Culture's consequences: International differences in work-related values". Newbury Park, CA: Sage.

Hofstede, G., (2001) "Culture's consequences: Comparing values, behaviors, institutions and organizations across nations." Thousand Oaks, CA: Sage Publications.

Hofstede, G., \& Minkov, M. (2010) "Long-versus short-term orientation: new perspectives." Asia Pacific business review, 16(4), 493-504.

International Monetary Fund (2009) "Guidance to Assess the Systemic Importance of Financial Institutions, Markets and Instruments: Initial Considerations."

Kotter, J. P., (2008) "Corporate culture and performance." Simon and Schuster.

Kwok, C. C., \& Tadesse, S., (2006) "National culture and financial systems." Journal of International Business Studies, $37(2), 227-247$.

Kanagaretnam, K., Lim, C. Y., \& Lobo, G. J., (2011) "Effects of national culture on earnings quality of banks." Journal of International Business Studies, 42(6), 853-874.

Laeven, L., Levine, R., (2009) "Bank governance, regulation and risk taking." J. Financ. Econ. 93, 259-275.

Mourouzidou-Damtsa, S., Milidonis, A., \& Stathopoulos, K., (2019) "National culture and bank risk-taking." Journal of Financial Stability, 40, 132-143.

Papanikolaou, N., Wolff, C., (2014) "The role of on - and off- balance-sheet leverage of banks in the late 2000 crisis". J. Financ. Stabil., 14 (1), 3-22.

Rochet, J. C., \& Tirole, J., (1996) "Interbank lending and systemic risk." Journal of Money, credit and Banking, 28(4), 733-762.

Ratnovski, L., (2013) "Liquidity and transparency in bank risk management." Journal of Financial Intermediation, 22(3), 422-439.

Schein, E.H., (1992) "Organizational culture and leadership." San Francisco, CA: Jossey-Bass.

Sackmann, S., (2010) "Assessment, evaluation, improvement: Success through corporate culture". Verlag Bertelsmann Stiftung.

Schwarcz, J., (2017) "Controlling Systemic Risk through Corporate Governance." Centre for International Governance Innovation (February).

Silva, W., Kimura, H., \& Sobreiro, V. A. (2017) "An analysis of the literature on systemic financial risk: A survey". Journal of Financial Stability, 28, 91-114.

Webb Cooper, E., (2009) "Monitoring and governance of private banks." Quart. Rev. Econ. Finance 49, $253-264$.

Yahanpath, N., \& Joseph, T., (2011) "A brief review of the role of shareholder wealth maximization and other factors contributing to the global financial crisis." Qualitative Research in Financial Markets, 3(1), 64-77. 